\title{
EVALUATION OF FIXATION OF ATLANTOAXIAL SUBLUXATION USING HARMS' TECHNIQUE
}

\section{Hussein Elsayed Moharram., Hamdy Ibrahim Khalil, Ahmed Elsayed Abdelbar, Ahmed Mohammed Elsayed, and Ahmed Essam Abdelmonem Anbar}

\begin{abstract}
Neurosurgery Department, Faculty of Medicine, Ain

Shams University

Corresponding:

Ahmed Essam Abdelmonem

Anbar

Mobile:

Email:

Received: $17 / 8 / 2020$

Accepted: 3/9/2020

Online ISSN: 2735-3540
\end{abstract}

\section{INTRODUCTION:}

The craniovertebral junction (CVJ), defined as the occiput, atlas, and axis, is a complex area that houses vital neural and vascular structures while achieving the most mobility of any segment within the spine ${ }^{(1)}$.

It represents the transition between the brain and cervical spine. The majority of the spine's rotation, flexion, and extension occur between the occiput, the atlas, and axis ${ }^{(2)}$.

The atlas lacks a vertebral body and instead articulates with the odontoid process or dens. The atlas also communicates inferiorly with the axis by flat, wide articular facets. The odontoid process and horizontal facets permit rotation of the skull, the predominate motion of the $\mathrm{C} 1-2$ vertebral junction $^{(1)}$.

The C1 and C2 vertebrae are called 'atypical vertebrae' and have unusual shape and architecture and a complex and important vertebral artery relationship. Injury to the artery during surgery can lead to catastrophic intra-operative bleeding and compromise to the blood flow can lead to unpredictable neurological deficits, which 


\section{Hussein Elsayed Moharram, et al.}

will depend on the adequacy of blood flow from the contralateral vertebral artery ${ }^{(3)}$.

Largely C1-C2 segment depends on the ligamentous supports and the integrity of the odontoid for its stability. Fusion of the C1$\mathrm{C} 2$ complex may be required in cases of atlantoaxial instability. Its extreme mobility places heavy demand on the atlantoaxial fixation construct for sufficient rigidity required for its fusion ${ }^{(4)}$.

The causes of C1-C2 instability are numerous and include trauma, congenital malformations, inflammatory arthritis, malignancies, skeletal dysplasias, rotatory subluxations and pharyngeal infections.

Clinically or radio graphically significant atlantoaxial subluxation is best treated by reduction and fusion of the $\mathrm{C} 1-\mathrm{C} 2$ joint. Posterior $\mathrm{C} 1-\mathrm{C} 2$ fusion has the advantage of a more rigid fixation with higher rates of fusion, avoiding need for postoperative halo, no placement of implant in the spinal canal, and possibility of its use in anomalies of odontoid process or the posterior $\operatorname{arch}^{(5)}$.

\section{AIM OF THE STUDY:}

This study aims at evaluation of Posterior Atlantoaxial fixation using Harms' technique in atlantoaxial subluxation regarding neck pain, fusion rates, neurological and radiographic outcomes.

\section{PATIENTS AND METHODS:}

This is a prospective study performed on 25 patients suffered from atlantoaxial subluxation treated by posterior atlantoaxial fixation using Harms' technique from 2015 to 2020 in Health Insurance hospitals and Ain Shams university hospitals.

\section{Inclusion criteria:}

Patients suffered atlantoaxial subluxation whether:
- Traumatic

- Congenital

- Inflamatory e.g.: Rheumatoid Arthritis.

- Reducible or irreducible

\section{Exclusion criteria:}

1. Subjects who had combined pathology of the C1-C2 facets and C1 lateral mass, such as comminuted fractures.

2. Subjects who had tumors destroying the C1 lateral masses that preclude screw placement were excluded from the study.

3. Vertebral artery anomalies.

4. C 2 pedicle pathology.

The following will be done for all patients:

1. Full history taking.

2. Preoperative clinical evaluation of the patients including complete neurological examination will be carried out.

3. Evaluation of patient's motor system using Japanese Orthopedic Association Scale (JOA).

4. Preoperative radiological evaluation:

- Plain X-ray anteroposterior, lateral, and flexion extension dynamic views.

- Computed tomography scan (CT) Cervical spine with saggital, coronal and $3 \mathrm{D}$ reconstruction, dynamic CT (in flexion and extension position).

- MRI cervical spine.

Lateral radiographs help to verify that the C1-C2 complex has been reduced adequately before the surgery. CT was done in all the cases to look at the transverse foramen of $\mathrm{C} 2$, understand the fracture anatomy, C2 isthmus size, space available for the cord and integrity of the $\mathrm{C} 1$ lateral masses. 


\section{Postoperatively:}

All subjects were kept in a Philadelphia collar for 12 weeks.

The subjects were followed up for neck pain, fusion rates, neurological and radiographic outcomes.

Follow up was at 3 months, then at 6 months and 1 year using:

- Plain X-ray cervical spine, CT cervical spine postoperative immediately, and MRI 3 months later.

\section{Surgical Technique:}

The patient is positioned prone using a Mayfield head holder (OMI, Inc., Cincinnati, OH). The neck is kept neutral with the head in the "military tuck" position. The arms are tucked at the sides and the shoulders retracted caudally using tape. A midline incision is made extending from the inion to the spine of $\mathrm{C} 3$ if atlantoaxial fixation is planned. A bilateral subperiosteal dissection of the paraspinal musculature is performed to expose the lateral margins of the facet joints at the $\mathrm{C} 2-\mathrm{C} 3$ level.

Dissection is continued laterally over the dorsal arch of $\mathrm{C} 1$. Bipolar cautery and hemostatic agents such as gelfoam and fibrillar collagen are used to control bleeding from the perivertebral venous plexus. The $\mathrm{C} 2$ nerve root is identified and mobilized inferiorly or can be sacrificed without significant neurological sequel. The lateral mass of $\mathrm{C} 1$ inferior to the $\mathrm{C} 1$ arch is exposed. The medial wall of the lateral mass is identified using a forward angle curette to identify the medial limit of screw placement.

The medial aspect of the transverse foramen can also be identified and serves as the lateral limit for screw placement. The entry point for screw placement is identified 3 to 5 $\mathrm{mm}$ lateral to the medial wall of the lateral mass, at the junction of the lateral mass and inferior aspect of the $\mathrm{C} 1 \mathrm{arch}$. The entry point may be varied depending on the distance between the medial wall of the lateral mass and the $\mathrm{C} 1$ transverse foramen. A high-speed drill with a $3 \mathrm{~mm}$ round burr is used to remove a small portion of the inferior aspect of the $\mathrm{C} 1$ arch overlying the entry point, to create a recess for the screw head and plate or rod. C2 nerve is cut down so give space for adequate visualization and preparing entry point for drilling. Assistant protects the vertebral artery with Penfield dissectors or similar instruments during drilling and screw placement.

Using fluoroscopy or image guidance, a $3 \mathrm{~mm}$ drill bit and guide are used to drill a hole with $10^{\circ}$ to $15^{\circ}$ of medial angulation to penetrate the anterior cortex of $\mathrm{C} 1$.

On lateral fluoroscopic imaging, the drill is aimed toward the anterior tubercle of $\mathrm{C} 1$ so that the drill penetrates the ventral cortex of the lateral mass midway between the superior and inferior facets of $\mathrm{C} 1$. The hole is tapped with a $3.5 \mathrm{~mm}$ tap. Caudal fixation points are then finalized. If a polyaxial screw-rod system is used, all screws are placed after which an appropriate sized and contoured rod is secured.

The $\mathrm{C} 2$ pedicle is defined as that portion of the $\mathrm{C} 2$ vertebra connecting the dorsal elements with the vertebral body. This is actually a very narrow area between the vertebral body and the pars interarticularis. The trajectory of the $\mathrm{C} 2$ pedicle screw is different from that of the $\mathrm{C} 2$ pars screw, being shallow in relation to the axial plane and more medially angulated. The entry point for $\mathrm{C} 2$ pedicle screw fixation is in the pars interarticularis, lateral to the superior margin of the $\mathrm{C} 2$ lamina. This will be approximately $2 \mathrm{~mm}$ superior and 1 to $2 \mathrm{~mm}$ lateral to the entry point for the $\mathrm{C} 2$ pars screw. 


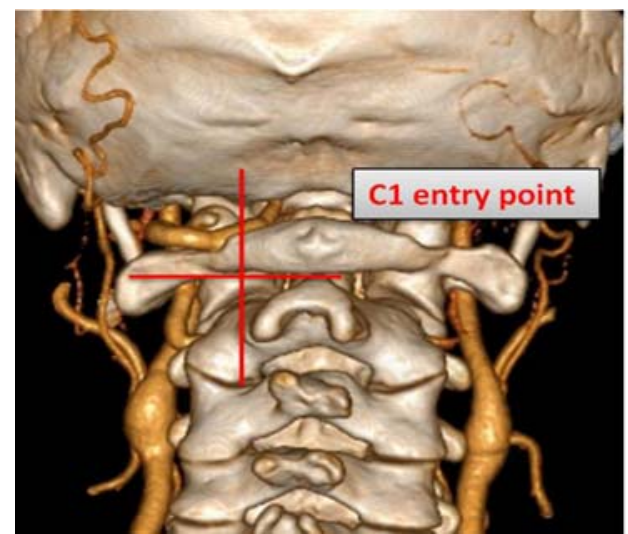

Screw entry points in C1 (left) and

The screw is placed with $15^{\circ}$ to $25^{\circ}$ of medial angulation, depending on the angulation of the pedicle as seen on CT imaging. The thick medial wall of the $\mathrm{C} 2$ pedicle will help redirect the screw if necessary and prevent medial wall breakout. The entry point can be adjusted based on the degree of medial angulation of the pedicle, as well as the rostrocaudal inclination of the pars interarticularis, which may be determined from the lateral radiographic view. This will generally be 3 to $4 \mathrm{~mm}$ lateral to the medial margin of the pars, which may be palpated with a curved spatula. C2 pedicle screws generally will be placed with a slight caudal-to-rostral inclination, which will point toward the ventral $\mathrm{C} 2$ body just below the base of the dens. This trajectory $\left(20^{\circ}\right.$ up angle) allows safe bicortical purchase if desired, providing greater resistance to screw pullout. The trajectory of the $\mathrm{C} 2$ pedicle screw will be medial to the $\mathrm{C} 2$ transverse foramen.

In both cases, an appropriate screw length is selected to achieve bicortical fixation. Once instrumentation placement is

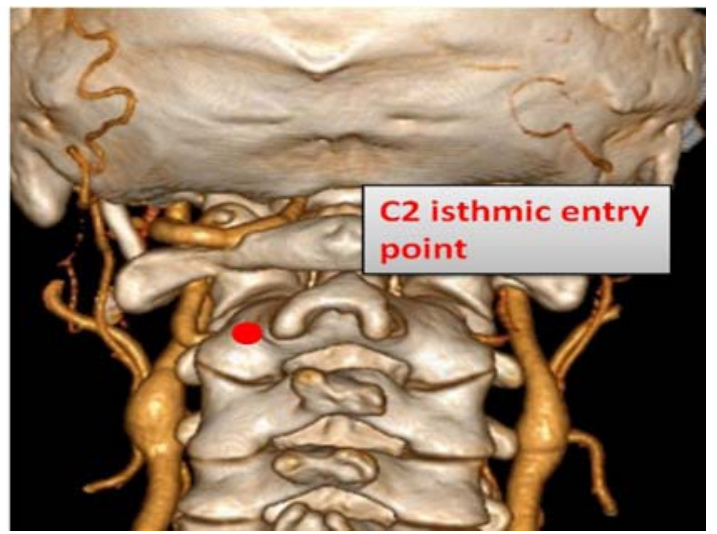

2 (right). (P. Bourdillon, et al, 2014)

complete, decompression is performed if necessary.

Finally, arthrodesis is performed by carefully decorticating the exposed surfaces of the C1-C2 joints with a high-speed drill, and then packing cancellous iliac crest autograft over these joints. A Hemovac drain is placed before wound closure.

\section{Statistical analysis:}

Data entry, processing and statistical analysis was carried out using Statistical package for social sciences (IBM-SPSS), version 24 (May 2016); IBM- Chicago, USA. Tests of significance (Kruskal-Wallis, Wilcoxon's, Chi square, logistic regression analysis, and Spearman's correlation) were used. Data were presented and suitable analysis was done according to the type of data (parametric and non-parametric) obtained for each variable. P- value: level of significance: $\mathrm{P}>0.05$ : Non-significant (NS), $\mathrm{P}$ $<$ 0.05: Significant (S), $\mathrm{P}<0.01$ : Highly significant (HS).

\section{RESULTS:}

Table 1: Shows mean age in this study.

\begin{tabular}{|c|c|c|c|c|}
\hline & Mean & Standard Deviation & Minimum & Maximum \\
\hline Age & 34.36 years & 17.30 & 13.00 years & 65.00 years \\
\hline
\end{tabular}




\section{Evaluation Of Fixation Of Atlantoaxial Subluxation Using Harms' Technique}

Table 2: Shows number of males and females in the study:

\begin{tabular}{|l|l|l|l|}
\hline \multicolumn{2}{|l|}{} & Count & $\%$ \\
\hline \multirow{2}{*}{ Sex } & Male & 14 & $56.0 \%$ \\
\cline { 2 - 4 } & Female & 11 & $44.0 \%$ \\
\hline
\end{tabular}

Table 3: Shows comparison of neck pain preoperatively and postoperatively using visual analogue score.

\begin{tabular}{|l|c|c|c|c|c|}
\hline & Mean & Standard Deviation & Minimum & Maximum & P value \\
\hline VAS pre-operative (Neck pain) & 8.48 & 0.51 & 8.00 & 9.00 & $<$ \\
VAS post-operative (Neck pain) & 2.48 & 0.51 & 2.00 & 3.00 & 0.001 \\
\hline
\end{tabular}

Regarding neck pain, preoperatively neck pain according to visual analogue score

ranged from 8 to 9 . Postoperatively neck pain improved and ranged from 2 to 3 .

Table 4: Mean of JOA score post and pre operative

\begin{tabular}{|l|c|c|c|c|c|}
\hline & Mean & Standard Deviation & Minimum & Maximum & P value \\
\hline JOA score pre-operative & 14.28 & 1.88 & 11.00 & 17.00 & $<0.001$ \\
\cline { 1 - 5 } JOA score post-operative & 16.12 & 0.93 & 13.00 & 17.00 & \\
\hline
\end{tabular}

Immediate postoperative radiological control, performed within 2 days of surgery, comprised thin-slice CT centered on C1-C2, with sagittal and axial studies. All screws were correctly positioned, with no cortical damage.

\section{CASES:}

\section{Case 1:}

\section{Pre OP. images:}

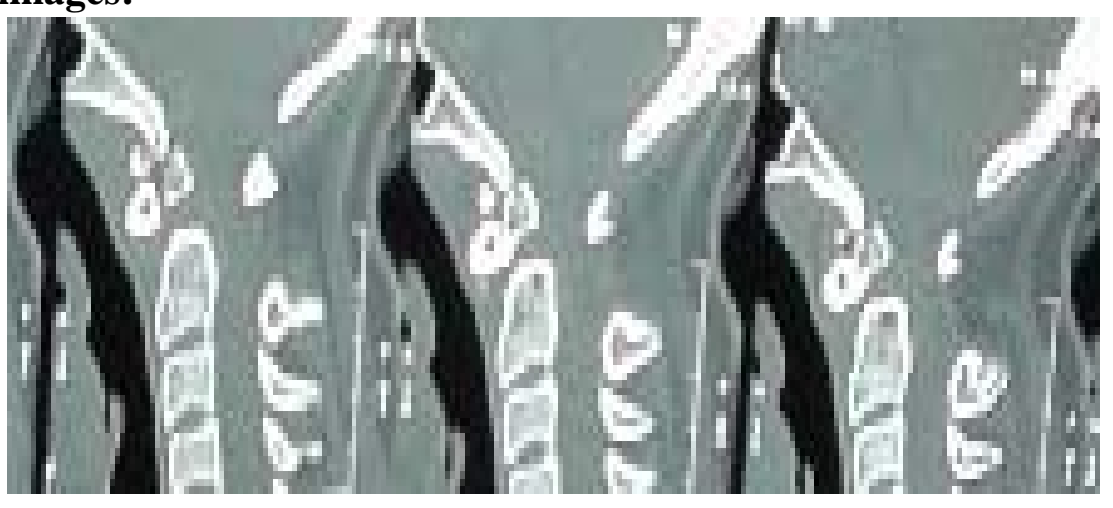

Patients were followed up at 3 months, 6 months and 1 year. Systematic CT control at 6 months found no non-union or displacement of material.

There were no cases of implant failure. At final follow-up, all patients demonstrated evidence of good fusion on radiographs. 


\section{Hussein Elsayed Moharram, et al.}

Post Op. images:

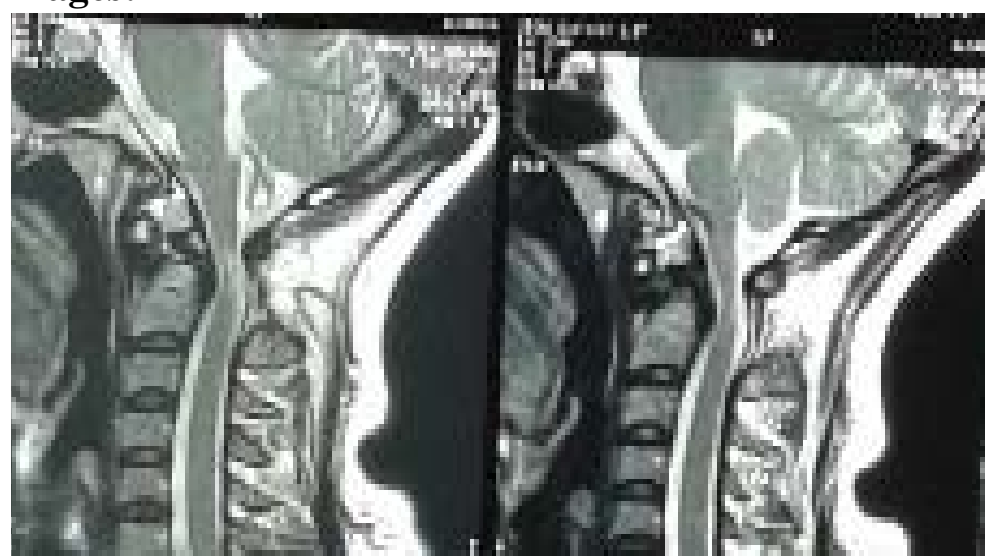

Case 2:

Pre op. images:
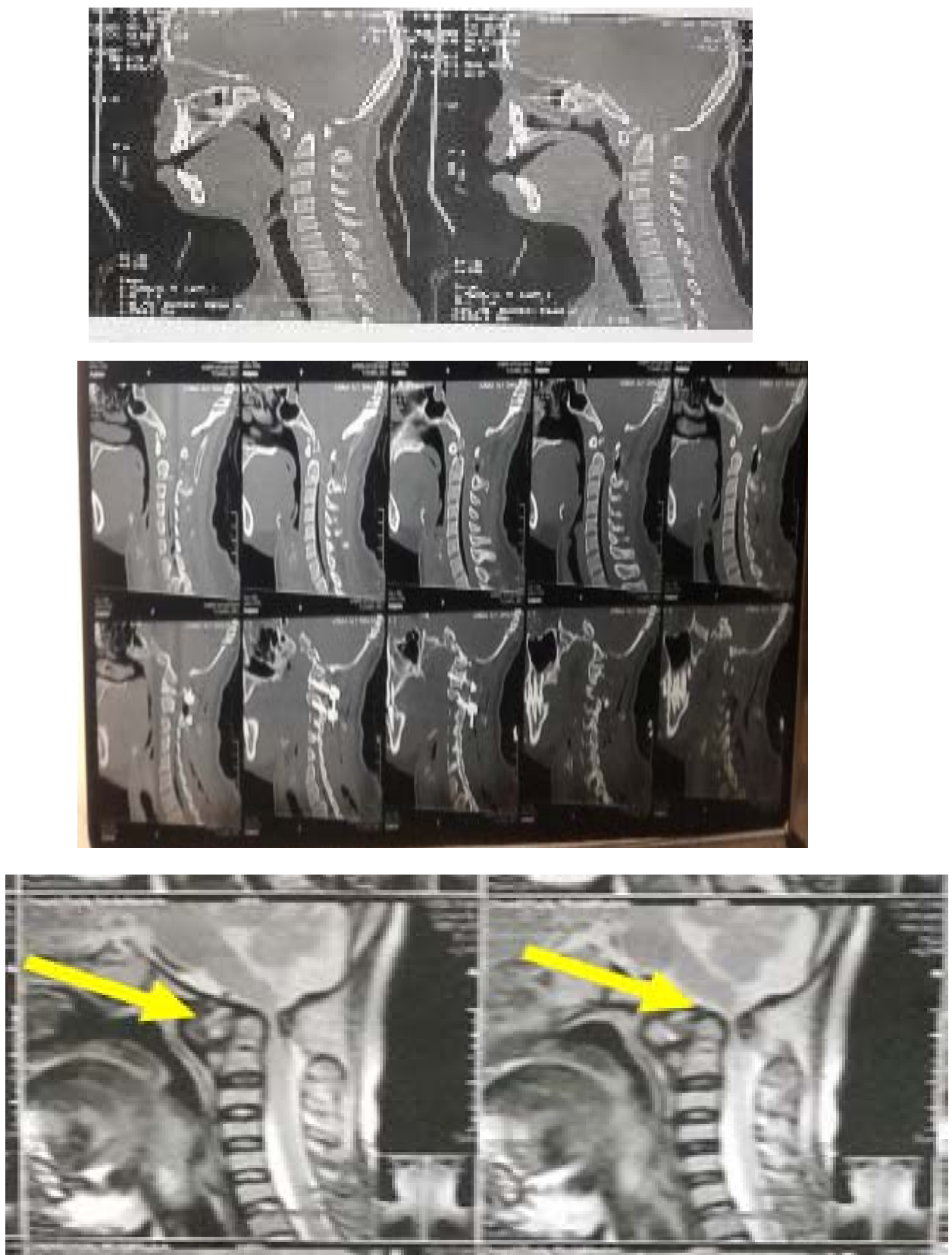


\section{Post op images:}

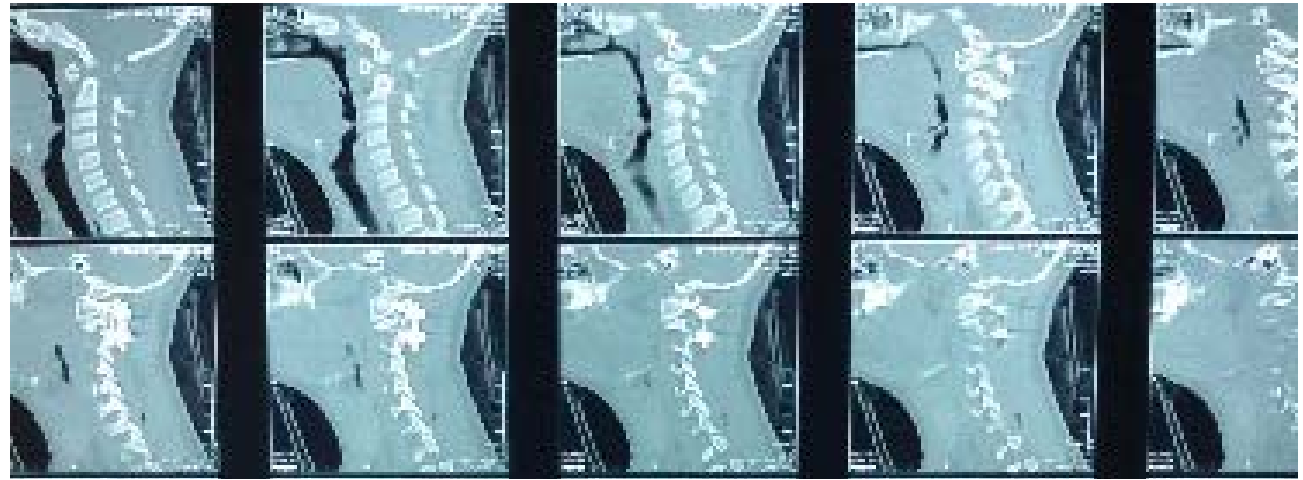

Intra operative image showed immediate reduction

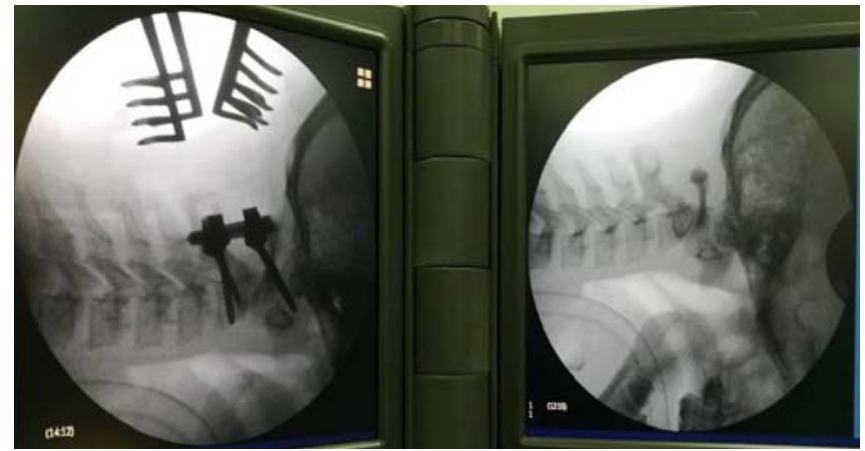

\section{DISCUSSION}

The craniovertebral junction encompasses a highly specialized anatomic arrangement that functionally allows increased mobility for the head. Injuries to the craniovertebral junction have the potential for acute catastrophic neurologic compromise as well as chronic instability.

The treatment of patients with atlantoaxial dislocation is a surgical challenge, and achieving a successful outcome for these patients is gratifying. The complications of surgery, however, are potentially lethal.

It is very important to understand the complex anatomy of the craniovertebral region, and to understand the underlying pathology that caused the instability in order to plan the suitable management for each case.

Identification of vertebral artery in preoperative imaging is very important to avoid vertebral artery injury during surgery.
Multi slice CT of cervical spine is helping in identification of vertebral foramen.

The techniques of fixation and stabilization of the craniovertebral region evolved during the last years as the technology makes anatomy and the biomechanical properties were evaluated and understood. Various methods of fixation have been described and used successfully in the treatment of atlantoaxial instability.

Newer techniques have evolved, with screws and plates or rods used for rigid internal fixation. Extensions of this technique include the use of occipitoatlantal transarticular screws alone.

Indications of occipito cervical fixation includes: Occipitoatlantal instability, cranial settling, basilar invagination, Occipitoatlantal dislocation, Destruction of occipitoatlantal joints, and Atlantoaxial instability with inability to fixate $\mathrm{C} 1, \mathrm{C} 2$, or both. Contraindications includes: Severe osteoporosis (relative contraindication), and 


\section{Hussein Elsayed Moharram, et al.}

destruction of bone surfaces (occiput, C1, C2).

Fixation of occiput affects movement occurred at occipitoatlantal joint which is flexion and extension of head by angle ranged between 23.0 to $24.5^{\circ}$. Alignment after occipito cervical stabilization merits careful consideration. Patients undergoing such a procedure will have lost significant mobility of the head and neck. At the extreme, patients fixated in too flexed or too extended a position may be unable to safely maintain the head in a neutral position, with difficulty ambulating or swallowing.

This study is a prospective study done from 2015 to 2019 on 25 patients suffered from atlantoaxial subluxation treated by posterior fixation using Harms' technique. Number of males in our study was 14 with a percentage $56 \%$ and females were 11 with a percentage $44 \%$.

Mean age in the study was 34.36 years with minimum age 13 years and maximum age 65 years and standard deviation 17.3 years. In Bourdillon et al., ${ }^{6}$ study on 26 patients underwent atlantoaxial fixation, number of males were 16 with percentage $61.5 \%$ and females were 10 with percentage $38.5 \%$. Mean age was 57 years and standard deviaton 19.3 years.

In a study by Ji Yong Kim et al., ${ }^{7}$ study on 27 patients underwent atlantoaxial fixation, number of males was 14 with percentage $51 \%$, and number of females was 13 with percentage $49 \%$. Mean age was 48.7 years, minimum was 32 and maximum was 67.

The causes of subluxation in cases of study were post traumatic, inflammatory process and congenital anomalies. There were 19 cases of traumatic cause (78\%), there were 4 cases of congenital cause mostly in our study patients were Down syndrome $(14 \%)$ and 2 cases of Rheumatic arthritis (8\%). In Bourdillon et al. ${ }^{6}$ study 11 of the 26 patients presented odontoid fracture non-union, 2 inflammatory pathologies ( 1 pannus on rheumatoid arthritis, 1 gout), 11 trauma (fracture or severe C1-C2 sprain) and 2 tumors (1 chordoma, 1 odontoid metastasis).

In a study by Ji Yong Kim et al., ${ }^{7} 13$ cases presented with $\mathrm{C} 1-\mathrm{C} 2$ instability (48\%), 10 cases with $\mathrm{C} 2$ fracture $(37 \%), 1$ case with Rheumatic arthritis (3.7\%), 2 cases with Os odentoidium (7.4\%) and 1 case of delayed non-union (3.7\%). The mean operative time was 126 minutes ranged from 90 to 180 minutes. The mean blood loss was $188 \mathrm{cc}$ ranged from $100 \mathrm{cc}$ to $300 \mathrm{cc}$. In Bourdillon et al., ${ }^{6}$ mean operative time was 160 minutes ranged from 75 minutes to 240 minutes, while blood loss was $260 \mathrm{cc}$ ranged from $90 \mathrm{cc}$ to $890 \mathrm{cc}$ study.

In Ji Yong Kim et al., mean operative time was 144 minutes, while blood loss was 229 cc. regarding clinical data, patients in the study presented with neck pain, neurologic affection including quadriparesis, hemiparesis and sphincter dysfunction.

Neck pain was assessed using Visual analogue score (VAS) of pain preoperatively and postoperatively. Preoperative mean value of VAS was 8.48 with standard deviation 0.51 , minimum was 8 and maximum was 9 . Postoperative mean value of VAS was 2.48 with standard deviation 0.51 , minimum was 2 and maximum was 3 , which is significant improvement. In Ji Yong Kim et al., ${ }^{7}$ mean value of pain score preoperatively was 7.6 and postoperatively improved to 3.2. Regarding neurological affection, 16 cases had a neurological problems, 11 case suffered quadriparesis which is $44 \%, 5$ cases suffered hemiparesis which is $20 \%$. 6 cases out of 25 cases suffered sphincter dysfunction which is $24 \%$. Patients in the study assessed using modified Japanese orthopedic association scale (mJOA), preoperative assessment of patients show mean was 14.28 and standard deviation was 1.88 , minimum was 11 and maximum was 17 . 
Postoperatively there was improvement in neurological status of patients, 10 patients improved immediately postoperative, 5 patients improved within 3 months and 1 patient didn't improve postoperatively. Postoperative assessment using mJOA scale showed mean was 16.12 and standard deviation was 0.93 , minimum was 13 and maximum was 17 . There is significant improvement.

In Bourdillon et al. ${ }^{6}$ study, 7 cases had neurological affection preoperatively, 5 cases showed clinical improvement. In $\mathrm{Ji}$ Yong Kim et al., ${ }^{7} 12$ cases had neurological affection preoperatively, 4 cases showed postoperative improvement.

Postoperative radiological control was done within 2 days after surgery, comprised thin-slice CT centered on C1-C2. All screws were correctly positioned, reduction happened in 24 cases $(96 \%)$. In postoperative radiological studies showed good fusion at 3 months \& 1 year. In Harms and Melcher study which showed good screw placement, reduction were achieved in all cases. Follow up showed fusion occurred in all cases.

In Bourdillon et al. ${ }^{6}$ study, radiologic studies showed screws in correct position in 22 cases (85\%), 4 cases cortical fracture was happened but less than $2 \mathrm{~mm}$. Three of the 4 fractures were of the $\mathrm{C} 0-\mathrm{C} 1$ joint line, and the fourth of the transverse canal at $\mathrm{C} 2$ without vascular impact. No revision operations were required and there were no clinical or radiological consequences (notably vascular or neurological). Patients were followed up at 6 months and 1 year. Systematic CT control at 6 months found no non-union or displacement of material.

In Ji Yong Kim et al., ${ }^{7}$ The proper positions of screws were observed in 20 patients of $27(74.0 \%)$. The overall fusion rate was 24 of 27 patients (89\%).

Occipital neuralgia(ON), or Arnold's neuralgia, was first described in 1821 either as a primary headache disorder or as a secondary condition due to varying craniocervical diseases, such as tumor, inflammation, degeneration, trauma, and deformity. It is characterized by paroxysmal burning and aching pain in the occipital region, which is supplied by greater, lesser, or third occipital nerves. PON can occasionally be mistaken for wound pain, which is as part of the normal postoperative course, and might be overlooked from the very beginning. PON should be suspected if the pain is strong in severity, long in duration, and extends to areas innervated by the $\mathrm{C} 2$ root. $\mathrm{MR}$ imaging can depict the neural foramen and the $\mathrm{C} 2$ nerve root, but it does not give diagnostic significance all the time.

Two prospective cohort studies compared the effect of $\mathrm{C} 2$ root transection and preservation on PON. The study by Yeom et al. $^{8}$ showed significantly higher average visual analogue scale (VAS) score for occipital neuralgia on last follow-up in the transection group although there was no significant difference between the groups preoperatively. The percentage of patients with increased neuralgia was significantly higher in the transection group than in the preservation group.

The study by Dewan et al. ${ }^{9}$ showed no significant difference in the percentages of PON or numbness between the two groups, but postoperative occipital numbness in the transection group had less effect on quality of life than that in the preservation group. The percentage of patients with numbness requiring medical therapy was significantly fewer in the transection group than in the preservation group. The mean pain related disability score was significantly higher in patients in the preservation group than in the transection group.

Traditionally, atlantoaxial instability has been treated by posterior wire stabilization and structural bone grafting. This technique does not provide sufficient immobilization 


\section{Hussein Elsayed Moharram, et al.}

of the atlantoaxial complex, resulting in nonunion rates up to $30 \%$ even with adjunctive halo vest immobilization.

Following Harms arthrodesis, we recommend temporary ( 6 weeks) use of a neck collar. There was one case of mortality, patient developed sudden disturbance of conscious level. Patient had a history of Rheumatic arthritis, preoperative ESR first hour 80, second hour 150. CT brain showed hypodense area in right cerebellar lobe with hypodensity in brain stem. Postoperative CT cervical spine shows screws in place with no indication of vertebral artery injury intraoperative.

\section{Conclusion:}

We thus advocate that this procedure only be performed by surgeons who are highly experienced in the treatment of atlantoaxial instability, and who have an intimate understanding of the anatomy of this region. Further biomechanical analysis of this technique should be performed to quantify the strength of constructs employing $\mathrm{C} 1$ lateral mass, $\mathrm{C} 2$ pedicle screws as compared with other fixation methods.

\section{REFERENCES:}

1. Bourdillon P, Perrin G, Lucas F, Debarge R, Barrey C. C1-C2 stabilization by harms arthrodesis: Indications, technique, complications and outcomes in a prospective 26case series. Orthopaedics \& Traumatology: Surgery \& Research 2014; 100: 225-231.
2. Dewan MC, Godil SS, Mendenhall SK, Devin CJ, McGirt MJ. C2 nerve root transection during $\mathrm{C} 1$ lateral mass screw fixation: does it affect functionality and quality of life? Neurosurgery 2014; 74(5):475-480.

3. Goel A, Sharma P, Dange N, Arvind GK. Techniques in the treatment of craniovertebral instability, Neurology India, 2005; 53(4):525-533.

4. Kim DH and Hilibrand AS. Rheumatoid arthritis in the cervical spine. J Am Acad Orthop Surg 2005; 13 (7):463-474.

5. Lopez AJ, Scheer JK, Leibl KE, Smith ZA, Dlouhy BJ, and Dahdaleh NS. Anatomy and biomechanics of the craniovertebral junction, Neurosurg Focus, 2015; 38(4):E2 $1-6$.

6. Raj B, Tarun G, Saravdeep SD, Sujit KT. Transarticular screw fixation for atlantoaxial instability - modified Magerl's technique in 38 patients, Journal of orthopedic surgery and research $2010 ; 5: 1$ 8 .

7. Taggard DA, Kraut MA, Clark CR, Traynelis VC. Case-control study comparing the efficacy of surgical techniques for C1-C2 arthrodesis. J Spinal Disord Tech, 2004; 17(3):189-94.

8. Wolfla CE. Anatomical, biomechanical, and practical considerations in posterior occipitocervical instrumentation. Spine J 2006; 6 (6): 225S-232S.

9. Yeom JS, Buchowski JM, Kim HJ, Chang BS, Lee CK, Riew KD. Postoperative occipital neuralgia with and without $\mathrm{C} 2$ nerve root transection during atlantoaxial screw fixation: a post-hoc comparative outcome study of prospectively collected data. Spine J 2013; 13(7):786-795. 


$$
\text { يوفر وضع الكتلة الجانبية C1 و المسامير اللولبية للعنق C2 طريقة بديلة مفيدة لتحقيق التثبيت المحوري. }
$$

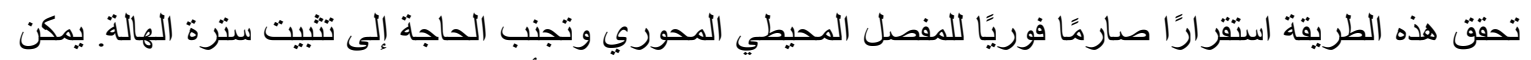

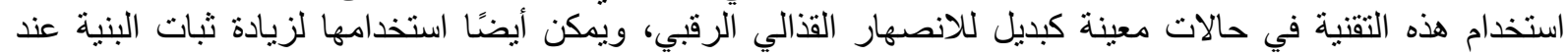

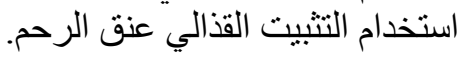

تقييم مسار الثريان الفقري مع التصوير المقطعي المحوسب قبل الجراحة واستخدام التنظير التألقي أثناء العملية أو التوحي توجيه الصور إلزامي عند استخدام هذه التقنية.

وضع المسمار C2 هو إجر اء ينطلب تقنيًا وقد يؤدي إلى مضاعفات خطيرة من إصابة الثريان الفقري إذا نم إجراؤه

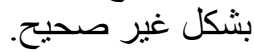
وبالتالي فإننا ندعو إلى أن ينم تنفيذ هذا الإجراء فقط من قبل الجراحئ احين الذين يتمتعون بخبرة عالية في علاج عدم

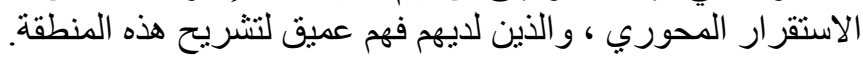

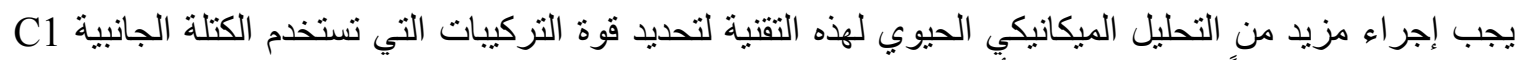
و البر اغي السنية C2 مقارنةً بطرق التنبيت الأخرى التيك. 